\section{(Q) \\ CrossMark}

\title{
Targeting coagulation activation in severe COVID-19 pneumonia: lessons from bacterial pneumonia and sepsis
}

\author{
Ricardo J. José $\mathbb{1}^{1,2}$, Andrew Williams ${ }^{1}$, Ari Manuel ${ }^{3}$, Jeremy S. Brown ${ }^{1,4}$ and \\ Rachel C. Chambers (1) 1
}

Affiliations: ${ }^{1}$ Centre for Inflammation and Tissue Repair, University College London, London, UK. ${ }^{2}$ Respiratory Medicine, Royal Brompton Hospital, London, UK. ${ }^{3}$ University Hospital Aintree, Liverpool, UK. ${ }^{4}$ Dept of Thoracic Medicine, University College London Hospital, London, UK.

Correspondence: Ricardo J. José, Centre for Inflammation and Tissue Repair, UCL Respiratory, University College London, 5 University Street, WC1E 6JF, UK. E-mail: r.joseducl.ac.uk

@ERSpublications

A large armamentarium of potentially beneficial anticoagulant agents exists, and well-designed randomised clinical trials are now needed to investigate the wide range of anticoagulant and antifibrinolytic therapies to determine the optimal strategy https://bit.ly/2CI459q

Cite this article as: José RJ, Williams A, Manuel A, et al. Targeting coagulation activation in severe COVID-19 pneumonia: lessons from bacterial pneumonia and sepsis. Eur Respir Rev 2020; 29: 200240 [https://doi.org/10.1183/16000617.0240-2020].

ABSTRACT Novel coronavirus disease 2019 (COVID-19), caused by severe acute respiratory syndromecoronavirus-2 (SARS-CoV-2), has rapidly spread throughout the world, resulting in a pandemic with high mortality. There are no effective treatments for the management of severe COVID-19 and current therapeutic trials are focused on antiviral therapy and attenuation of hyper-inflammation with anticytokine therapy. Severe COVID-19 pneumonia shares some pathological similarities with severe bacterial pneumonia and sepsis. In particular, it disrupts the haemostatic balance, which results in a procoagulant state locally in the lungs and systemically. This culminates in the formation of microthrombi, disseminated intravascular coagulation and multi-organ failure. The deleterious effects of exaggerated inflammatory responses and activation of coagulation have been investigated in bacterial pneumonia and sepsis and there is recognition that although these pathways are important for the host immune response to pathogens, they can lead to bystander tissue injury and are negatively associated with survival. In the past two decades, evidence from preclinical studies has led to the emergence of potential anticoagulant therapeutic strategies for the treatment of patients with pneumonia, sepsis and acute respiratory distress syndrome, and some of these anticoagulant approaches have been trialled in humans. Here, we review the evidence from preclinical studies and clinical trials of anticoagulant treatment strategies in bacterial pneumonia and sepsis, and discuss the importance of these findings in the context of COVID-19.

\section{Introduction}

Novel coronavirus disease 2019 (COVID-19) first emerged in Wuhan, China, and has rapidly spread across the globe. COVID-19 is caused by severe acute respiratory syndrome-coronavirus-2 (SARS-CoV-2) and, as of August 7, 2020, there have been $\sim 19$ million reported cases and 700 thousand deaths [1]. The only treatment thus far to demonstrate a reduction in mortality of severe COVID-19 is dexamethasone [2]. The antiviral remdesivir has been shown to reduce hospital length of stay [3]. Therefore, identifying successful therapeutic strategies still remains a major ongoing challenge.

Provenance: Submitted article, peer reviewed.

Received: 26 July 2020 | Accepted after revision: 20 Aug 2020

Copyright $\odot$ ERS 2020. This article is open access and distributed under the terms of the Creative Commons Attribution Non-Commercial Licence 4.0 
The pathogenesis of severe COVID-19 pneumonia has similarities with that of severe bacterial pneumonia, with both causing severe hypoxia that often requires ventilatory support. Both are characterised by extensive inflammatory cell recruitment to the lungs, a potent acute phase reaction and raised levels of pro-inflammatory cytokines (figure 1) [4, 5]. Severe COVID-19 pneumonia and severe bacterial pneumonia are both associated with widespread activation of the coagulation system, evidenced by elevated activated partial thromboplastin time (APPT) and prothrombin time (PT) and markedly elevated D-dimer levels, with raised levels of the latter being associated with poor prognosis [6-9]. Evidence of disseminated intravascular coagulation is seen frequently in patients at increased risk of death from COVID-19 [8]. In severe COVID-19, the clinical relevance of activation of the coagulation system is evidenced by a high incidence of pulmonary and peripheral venous thromboembolic (VTE) disease, stroke and acute coronary syndromes, even in patients receiving prophylactic heparin $[8,10,11]$. The development of microthrombi in lung capillaries [12] may partially explain the profound hypoxia seen in some patients with COVID-19, and similar microthrombi may contribute to renal and cardiac involvement. Recent studies suggest that the rapid accumulation of neutrophil extracellular traps in the microvessels of patients with severe COVID-19 results in occlusion of these vessels and promotes microthrombosis [13].

Although endothelial dysfunction occurs in bacterial pneumonia and sepsis, it is pronounced in COVID-19, with SARS-CoV-2 having a direct effect on the endothelium. Post mortem studies have shown evidence of intracellular virus and microangiopathy [12]. SARS-CoV-2 uses the angiotensin-converting enzyme (ACE)-2 receptor to enter the host cells and activates the renin-angiotensin system, which can induce a prothrombotic state [14]. Furthermore, the host inflammatory response to the virus promotes activation of coagulation and reduced fibrinolysis. Older age, low lymphocyte count, prolonged PT and APPT, and admission to the intensive care unit have been identified as risk factors for thrombosis [15].

COVID-19 pneumonia is characterised by increases in multiple cytokines, including tumor necrosis factor (TNF) and interleukin-6 (IL-6) [16], which are potent activators of the tissue factor (TF)-dependent coagulation cascade [17-19]. Activation of the coagulation system is known to be pro-inflammatory and could drive further increases in inflammation; in tissues with a delicate architecture such as the distal lung, this can be highly detrimental, impairing gas exchange [20] and culminating in acute respiratory distress syndrome (ARDS) [21, 22]. The extensive activation of coagulation in patients with severe COVID-19 could stimulate further inflammation via the mechanisms described below, resulting in a positive feedback loop that maintains high levels of inflammation for a prolonged period. Hence, effective anticoagulation strategies may prevent complications associated with aberrant clotting, attenuate coagulation-induced exaggerated inflammatory responses and potentially reduce the severity and extent of pulmonary infiltrates.
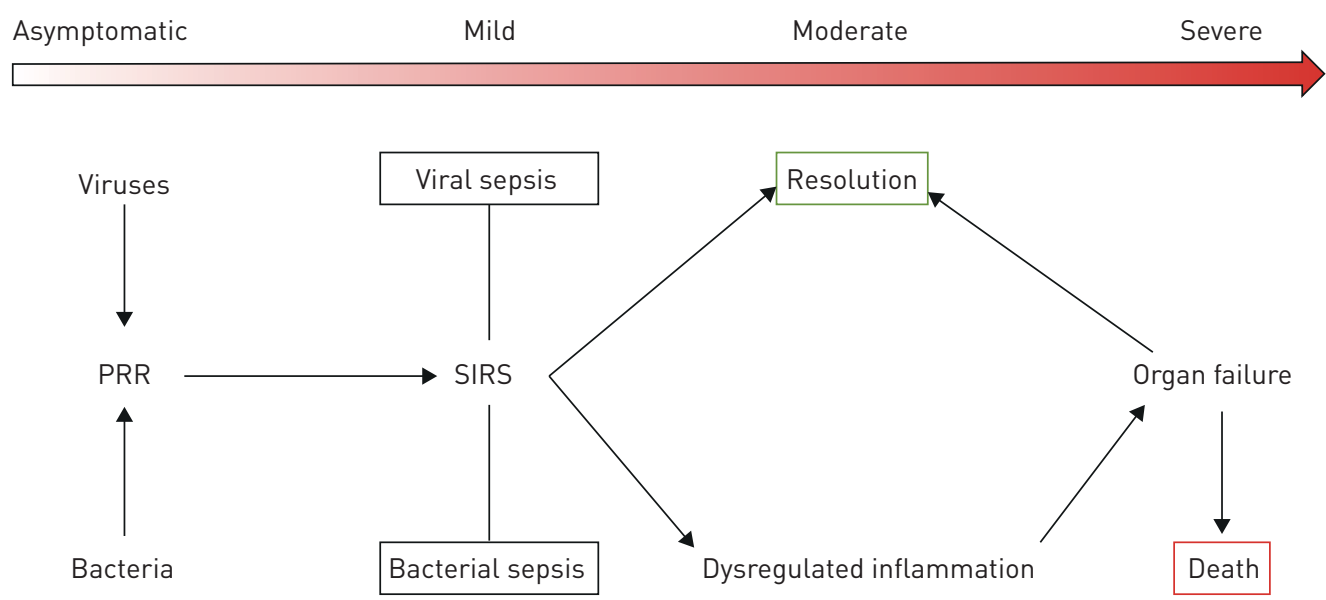

FIGURE 1 Similarity in progression of severe viral and bacterial pneumonia. During viral and bacterial infection, the pathogens are recognised by host pathogen recognition receptors (PRR) on the surface of epithelial cells, mononuclear phagocytes and other cell types, resulting in initiation of various inflammatory cascades triggering systemic inflammatory response syndrome (SIRS). At this stage patients will have viral/ bacterial sepsis with life-threatening organ dysfunction. Most individuals will clear the pathogen (with antimicrobial/antiviral therapyl and the body resolves the inflammation. Others, however, will not be able to clear the pathogen, or despite clearance of the pathogen will continue to exhibit dysregulated inflammatory responses that are unabated, resulting in tissue injury and organ failure. Of these patients, some receiving supportive care will recover and some will die. 
Although less clinically evident than in COVID-19, severe bacterial pneumonia and sepsis are also associated with activation of coagulation locally in the lungs and systemically, and are associated with bystander tissue injury and correlate negatively with survival $[9,23,24]$. As a consequence, therapies that modulate inflammatory responses caused by activation of coagulation have been extensively investigated in bacterial pneumonia and sepsis. Several anticoagulant therapeutic strategies for treating pneumonia, sepsis and ARDS have been identified and some of these anticoagulants have been trialled in humans. The high frequency of coagulation abnormalities and prolonged inflammation that occurs in severe COVID-19 suggests these therapies are attractive potential therapies.

Here, we review the evidence from preclinical studies and clinical trials of anticoagulant treatment strategies in bacterial pneumonia and sepsis and discuss how these data could be relevant for managing COVID-19 pneumonia. The data will be discussed in relation to 1) activation of the TF-thrombin generation pathway, 2) endogenous anticoagulants and 3) coagulation-inflammation crosstalk (figure 2).

\section{The TF-dependent pathway}

The TF pathway is the main initiator of procoagulant activity secondary to tissue injury and inflammation, and it plays an important role in pneumonia and ARDS [25, 26]. TF is a transmembrane glycoprotein expressed by mononuclear cells, endothelial cells, fibroblasts, vascular smooth muscle cells and alveolar epithelial cells but it can also be detected in extracellular fluids and in cell-derived microparticles shed from activated cells [27-29]. Under normal physiological conditions, TF will only come into contact with blood or circulating coagulation zymogens after vascular injury and disruption of the endothelial barrier $[30,31]$. TF binds to and activates coagulation factors VII to VIIa, forming the TF-VIIa complex. This initiates the TF-dependent pathway of coagulation by activating coagulation factor $\mathrm{X}$ to $\mathrm{Xa}$ and then binding factor Xa to form the TF-VIIa-Xa ternary complex. The TF-VIIa-Xa ternary complex converts prothrombin (factor II) to thrombin (factor IIa), a process that is sustained and increased in efficiency by positive feedback through activation of coagulation factors V and VIII, which are non-enzymatic cofactors that activate factor $\mathrm{X}[32,33]$. Thrombin converts fibrinogen to fibrin, the main constituent of clots, and is also the main physiological activator of proteinase-activated receptor-1 $\left(\mathrm{PAR}_{1}\right)$, the major high-affinity thrombin receptor that promotes multiple downstream cellular responses involved in tissue repair. However, when dysregulated, these cellular responses promote inflammation and lead to disruption of the epithelial and endothelial barriers and the development of fibrosis in multiple organs, including the lung, kidney and liver [34], thereby contributing to disease pathogenesis during severe infections.

\section{TF pathway inhibitors}

TF and factor VIIa levels are elevated in the bronchoalveolar lavage fluid of patients with severe pneumonia, and the central role of TF for initiating coagulation makes it an attractive target for therapeutic intervention against the potential negative consequences of coagulation activation. Tissue factor pathway inhibitor (TFPI) is a central endogenous regulator of TF pathway activity and thrombin generation. This glycoprotein is mainly expressed by endothelial cells and platelets and acts by directly inhibiting factor Xa. The Xa-TFPI complex subsequently also inhibits the TF-VIIa complex. In preclinical non-human primate models of endotoxaemia, blockade of TF-VIIa, using a competitive inhibitor of TF (site-inactivated factor VIIa), inhibits the TF pathway and reduces lung inflammation and deposition of fibrin $[35,36]$. A phase II clinical trial of recombinant human TFPI (rhTFPI; Tifacogin) in patients with severe sepsis decreased concentrations of IL-6, an important pro-inflammatory cytokine that is increased in COVID-19 pneumonia and a major target in ongoing clinical trials [37, 38]. However, in the Optimised Phase III Tifacogin (rTFPI) in Multicenter International Sepsis Trial (OPTIMIST phase III) for patients with severe sepsis with a high international normalised ratio $(\geqslant 1.2)$, rhTFPI did not improve 28-day mortality, despite reducing evidence of inflammation [39]. Administration of rhTFPI and heparin concomitantly was associated with increased bleeding, although a post hoc analysis did suggest rhTFPI improved survival in patients with severe community-acquired pneumonia (CAP) for whom the microbiological aetiology was known and heparin had not been given [40]. However, the subsequent Recombinant Tissue Factor Pathway Inhibitor in Severe Community-Acquired Pneumonia (CAPTIVATE) trial [41] did not demonstrate improved survival for patients with severe CAP treated with rhTFPI. Although TFPI was largely disappointing in the setting of sepsis, the advantages of targeting the TF pathway in preventing the development of capillary microthrombi, as well as inflammation, might outweigh potential risks.

\section{Endogenous anticoagulants and treatment of severe pneumonia and ARDS}

Activation of the coagulation system is countered by endogenous anticoagulants, which act either alone or in concert to limit coagulation. A number of endogenous anticoagulants, including anti-thrombin (AT) and activated protein C (APC), have been trialled in severe pneumonia and ARDS, on the basis that they 


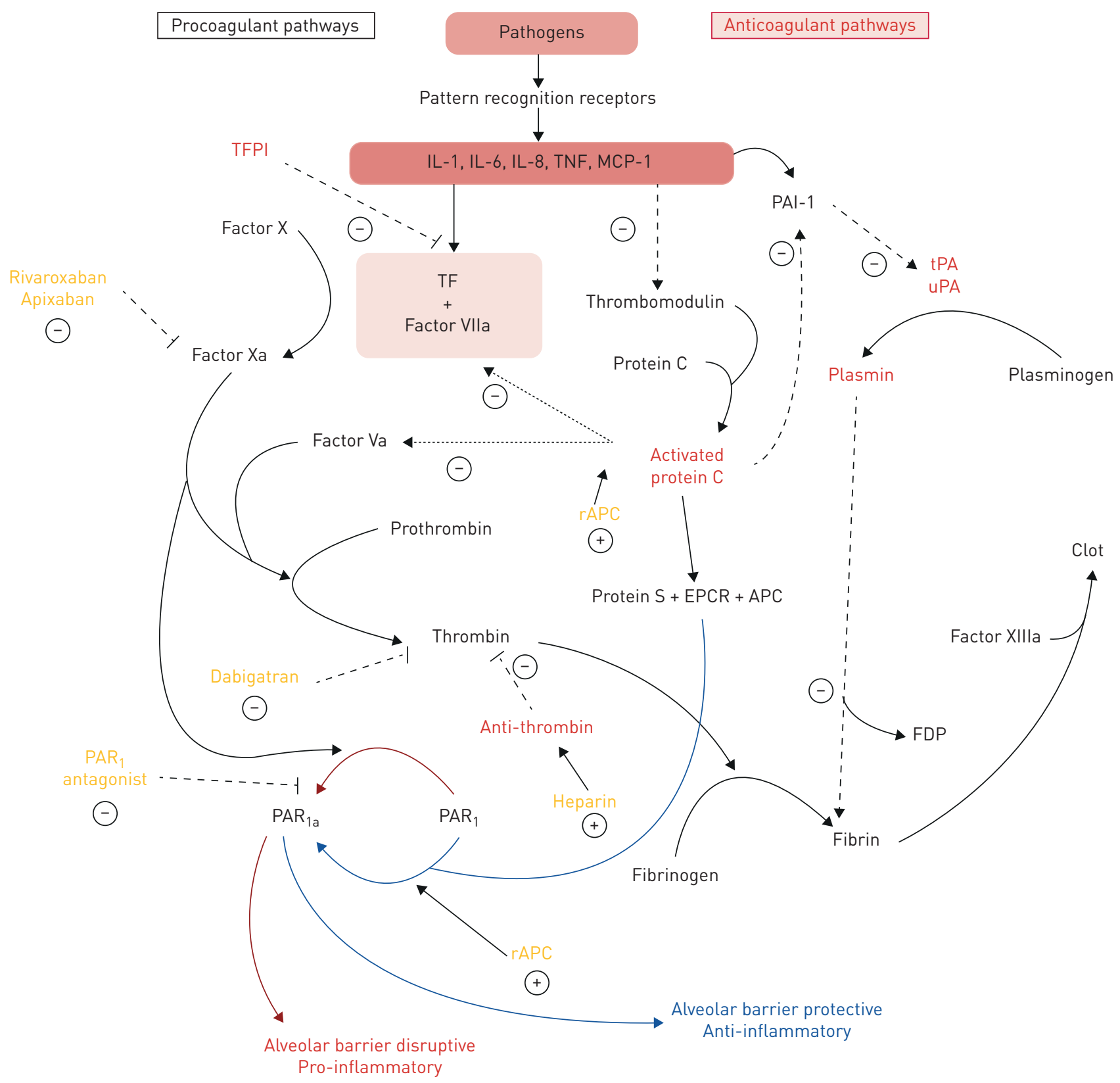

FIGURE 2 Activation of the coagulation cascade and endogenous anticoagulants. Pathogens in the lungs are recognised by pattern recognition receptors that initiate a pro-inflammatory response and expression of tissue factor (TF) allowing factor VIla to come in to contact with TF. TF-VIla activates factor $\mathrm{X}$ that binds to TF-VIla to form a ternary complex that converts prothrombin to thromobin (factor Ila). Factor Va binds to the ternary complex to form the prothrombinase complex and to platelets and factor Xa to form the major prothrombinase complex that generates the large amounts of thrombin necessary for fibrin clot formation. Thrombin also increases expression of thrombomodulin on endothelial cells and activates proteinase-activated receptor- $1\left(\mathrm{PAR}_{1}\right)$, the major thrombin receptor. Activation of PAR ${ }_{1}$ by thrombin leads to downstream signalling that is pro-inflammatory and leads to disruption of the alveolar barrier (brown). Activation of $\mathrm{PAR}_{1}$ by activated protein $\mathrm{C}$ (APC) leads to signalling that has barrier-protective and anti-inflammatory effects (blue). TFPI: tissue factor pathway inhibitor; IL: interleukin; TNF: tumor necrosis factor; MCP: monocyte chemoattractant protein; PAl: plasminogen activator inhibitors; tPA: tissue-type plasminogen activator; uPA: urokinase-type plasminogen activator; EPCR: endothelial protein C receptor; FDP: fibrin degradation products.

were shown to be protective against lung injury in experimental animal models by reducing fibrin generation and attenuating neutrophil recruitment [42-46].

\section{Anti-thrombin}

AT inactivates thrombin and factor $\mathrm{Xa}$ and has been shown to reduce systemic (after intravenous administration) and bronchoalveolar (after both intravenous and nebulised administration) thrombin and fibrin levels and reduce lung injury in preclinical models $[42,46]$. However, the clinical data currently do not support using AT as a treatment to improve lung injury. The KyperSept trial of high-dose AT 
treatment in severe sepsis [47] showed no effect on 28-day mortality, and an increased risk of bleeding events in the AT-treated participants was observed, particularly in those who received concomitant heparin. Yet, a subgroup analysis revealed that the AT-treated group that had not received concomitant heparin had a $15 \%$ improvement in 90 -day mortality compared to those treated with heparin. Nonetheless, a meta-analysis of 20 trials of a heterogeneous population of critically ill patients concluded that AT should be avoided owing to the risk of bleeding complications [45]. Natural or pharmacological thrombin inhibitors have not been tested in clinical trials in the setting of pneumonia and potential clinical translation has been inferred from studies of AT in sepsis, in which pneumonia is the leading cause in a large proportion of cases. In terms of extrapolation to COVID-19 pneumonia, we would propose that the current evidence would also argue against the use of AT, particularly if co-administered with heparin. Heparin alone, which exerts its anticoagulant effects via the activation of AT, is currently being evaluated in multiple trials in the context of COVID-19 pneumonia. This includes evaluation of a systemic prophylactic dose and a full therapeutic dose of low molecular weight heparin (LMWH). In H1N1 ARDS, anticoagulation with systemic heparin significantly reduced the high incidence of VTE [48]. Heparin also exerts anti-inflammatory and antiviral properties $[49,50]$. However, the route of administration of heparin is likely to be critical. Nebulised heparin did not attenuate inflammation in a murine model of pneumonia [42], and, in clinical trials in patients with or at risk of ARDS, nebulised heparin had no major impact on physiological variables nor a beneficial effect on mortality, although it increased ventilator-free days [51-53].

\section{Activated protein C}

APC plays a critical role in terminating coagulation by proteolytically inactivating factors Va and VIIIa, and has been widely investigated in the context of sepsis [54-56]. Once the coagulation cascade is activated, thrombin binds to thrombomodulin and, facilitated by the endothelial protein $\mathrm{C}$ receptor (EPCR), protein $\mathrm{C}$ is activated. APC then binds to the EPCR and, together with its co-factor protein $\mathrm{S}$, forms the EPCR-APC-protein S complex that binds and degrades factor Va and factor VIIIa [57], providing negative feedback for thrombin generation. APC also exerts pro-fibrinolytic and anti-inflammatory effects [57, 58]. Preclinical studies support a beneficial effect of APC administration, showing that rhAPC attenuates tissue injury and improves survival in models of sepsis and lung injury [59-61]. For example, in murine models of indirect lung injury (intravenous injection of lipopolysaccharide) and direct lung injury (Streptococcus pneumoniae infection), nebulised rhAPC specifically reduced local bronchoalveolar thrombin and fibrin generation without affecting intravascular thrombin generation or fibrinolytic activity [46] and without adversely affecting bacterial clearance [46]. This provides proof-of-principle that targeting the alveolar epithelium locally with nebulised rhAPC can attenuate coagulation activation without compromising host defence.

In clinical studies, systemic, rather than nebulised, delivery of APC has had initially promising results. In the original landmark PROWESS study, intravenous infusion of rhAPC (drotrecogin alpha (activated) (DrotAA)) significantly reduced 28-day all-cause mortality in patients with sepsis (secondary to CAP) by $28 \%$ and reduced the resolution time of respiratory failure [22]. This resulted in the Infectious Diseases Society of America/American Thoracic Society recommending APC for the treatment of refractory septic shock due to CAP [62]. Although APC reduced coagulation activation and lung injury scores in a study of 27 patients with ARDS [63, 64], in a subsequent randomised controlled trial APC did not improve the clinical outcomes of ARDS patients [65] or of patients with sepsis and low of risk of death [66]. Furthermore, a meta-analysis of five studies involving 5101 participants concluded that APC was associated with higher risk of bleeding and should not be used in patients with severe sepsis or septic shock [67]. Importantly, the PROWESS-Shock study [55] failed to demonstrate an improvement in survival in patients with septic shock and eventually led to the withdrawal of DrotAA (Xigris) from the market. However, the significant differences in patient characteristics between the PROWESS trials has led to the recommendation that a trial of DrotAA should be repeated using an optimised study design [68], and this could include a trial in a less heterogeneous high-risk population, such as COVID-19 pneumonia. The preclinical and clinical data suggest nebulised rhAPC may not carry the same bleeding liability as intravenous administration and may be an appropriate route of drug administration. Alternatively, the bleeding risk could be mitigated using an rhAPC variant with $<10 \%$ anticoagulant activity [69], which in preclinical studies was as effective as wild-type APC in improving survival of mice in sepsis models [69].

In a small study of 11 COVID-19 patients, most had increased endogenous APC levels [70]; however, four patients had lower APC levels and in this subgroup of patients, particularly those with septic shock or at high risk of death, administration of rhAPC might warrant further investigation.

\section{Endogenous fibrinolytics}

Fibrin deposition and clearance is regulated by the control of plasmin activity, which in turn is regulated by the relative balance between plasminogen activators and plasminogen activator inhibitors (PAI)-1, -2 
and -3. Plasminogen is mainly synthesised in the liver and converted into plasmin by the serine proteinases tissue-type plasminogen activator (tPA) or urokinase-type plasminogen activator (uPA). Several preclinical and clinical studies have demonstrated elevated levels of PAI-1 in pneumonia [30, 71, 72]. However, preclinical studies on the effects of PAI-1, tPA and uPA in murine models of pneumonia suggest the outcome is pathogen dependent. For example, in a Klebsiella pneumoniae pneumonia model, PAI-1 improved bacterial clearance and reduced mortality [73], but neither PAI-1 nor plasmin appeared to have a role in mouse models of $S$. pneumoniae [72] or Pseudomonas aeruginosa pneumonia [74]. Instead, the urokinase plasminogen activator receptor axis promoted host defence against $S$. pneumoniae by recruiting neutrophils to the alveoli and enhancing neutrophil-mediated bacterial killing [75]. Furthermore, in a model of sterile lung injury, tPA administration reduced alveolar leak but had no effect on pulmonary inflammation [76]. Data are limited regarding the role of this system in viral respiratory infection models but in a study of influenza A infection, the absence of plasminogen reduced inflammation [77]. A recent meta-analysis of preclinical studies of fibrinolytics in acute lung injury suggested increased fibrinolysis, attenuated inflammation and alveolar leak, and improved survival [78].

There are limited clinical data on the efficacy of targeting fibrinolysis in patients with severe infections or ARDS. However, patients with ARDS display evidence of a marked reduction in fibrinolysis, with evidence of reduced uPA activity and increased PAI-1 levels in bronchoalveolar lavage fluid [30]. Furthermore, one study demonstrated a shorter length of stay in the intensive care unit and improved survival in ARDS patients treated with nebulised streptokinase [79]; this pathway may represent an interesting target for the management of COVID-19-induced lung injury. Two trials targeting this pathway are currently underway, one in the UK (nebulised r-tPA) and another in the USA (alteplase) (NCT04356833, NCT04357730).

\section{PARs mediate the interplay between coagulation and inflammation}

The discovery of the PARs in 1991 represented a watershed moment in our understanding of the mechanism by which coagulation proteinases directly influence cell function. PARs are seven transmembrane domain G-protein-coupled receptors that have unique mechanisms of activation, which involves limited proteolysis of their amino-terminal exodomains to unmask a tethered ligand. Four PARs $\left(\mathrm{PAR}_{1-4}\right)$ are differentially expressed on lung-resident cells, including lung epithelial cells, endothelial cells and fibroblasts, as well as on recruited monocytes and neutrophils following tissue injury. Thrombin is a major activator of $\mathrm{PAR}_{1}$ and $\mathrm{PAR}_{3}$, whereas factor $\mathrm{Xa}$ and the potent TF-Xa-VIIa ternary complex activate $\mathrm{PAR}_{1}$ and $\mathrm{PAR}_{2}$ [80]. $\mathrm{PAR}_{1}$ can also be activated by the EPCR-APC complex [81], plasmin [82] and matrix metalloprotease-1 [83], whereas trypsin and tryptase can activate $\mathrm{PAR}_{2}$ [80].

Activation of $\mathrm{PAR}_{1}$ induces the expression of a host of inflammatory cytokines, chemokines and growth factors that influence inflammatory cell trafficking, leukocyte activation and endothelial permeability [84, 85]. However, $\mathrm{PAR}_{1}$ downstream signalling is highly context dependent and influenced by both the nature and the extracellular concentration of activating proteinases [86]. For example, in vitro studies using exogenously added proteinases have shown that thrombin increases vascular permeability via $\mathrm{PAR}_{1}$ activation and coupled signalling of the S1P3 receptor [87]. Conversely, APC inhibits thrombin-mediated vascular hyper-permeability via $\mathrm{PAR}_{1}$ activation and signalling via the S1P1 receptor $[86,88]$. During infection the deleterious thrombin- $\mathrm{PAR}_{1}$ signalling responses appear to predominate over protective APC-PAR 1 signalling responses because endogenous APC levels are depleted and APC has 500 times lower affinity and efficiency for cleaving $\mathrm{PAR}_{1}$ compared to thrombin $[89,90]$. The differential effects of PAR-1 activation by APC or thrombin are also explained by differential cleavage of the $\mathrm{PAR}_{1} \mathrm{~N}$-terminus. Thrombin cleaves $\mathrm{PAR}_{1}$ at Arg41, whereas APC cleaves $\mathrm{PAR}_{1}$ at Arg41 and Arg46, with preferential cleavage at the latter site mediating the cytoprotective effects of APC [91, 92]. Hence, in the presence of increased thrombin generation, as often seen in severe pneumonia, the beneficial effects of low levels of endogenous APC may be overcome by the barrier-disruptive effects of thrombin-induced $\mathrm{PAR}_{1}$ cleavage.

In preclinical studies, survival from sepsis appears to be related to the time of activation of $\mathrm{PAR}_{1}$ [93]; mice treated early with a $\mathrm{PAR}_{1}$ antagonist were protected against thrombocytopaenia and had reduced thrombin levels and improved survival [93]. S. pneumoniae pneumonia in $\mathrm{PAR}_{1}$-knockout mice exhibited evidence of reduced lung injury and neutrophil recruitment without any effect on bacterial clearance [94], whereas the $\mathrm{PAR}_{1}$ antagonist vorapaxar reduced neutrophilic inflammation; TNF, IL-1 $\beta, \mathrm{C}-\mathrm{C}$ motif chemokine ligand 2 (CCL2) and CCL7 levels; coagulation activation; and vascular permeability (alveolar leak) without adversely affecting bacterial clearance. Murine studies of viral infection, including influenza $[95,96]$, suggest $\mathrm{PAR}_{1}$ is required for host control of virus load initially, but if viral replication is left unrestricted $\mathrm{PAR}_{1}$ promotes inflammation and increases mortality. These preclinical findings support the rationale that blockade of $\mathrm{PAR}_{1}$ may be beneficial in attenuating pathogen-induced hyper-inflammatory responses and in maintaining integrity of the alveolar endothelial barrier, but that the benefits of this treatment may differ with the timing of treatment and the causative pathogen. 
The potential of targeting coagulation in COVID-19

As previously highlighted, severe COVID-19 is associated with overwhelming clinical complications of coagulation activation. A retrospective study of 107 patients who had received at least 1 month of anticoagulation therapy prior to SARS-COV-2 infection demonstrated that none developed clinically relevant thrombotic complications [97]. Prophylactic dose heparin is therefore recommended for all patients admitted to hospital with COVID-19 [98]. The enhanced inhibition of thrombin with higher doses of LMWH may further benefit patients by subsequently reducing the downstream signalling involved in inflammation, although the bleeding risk would need to be carefully considered. Clinical trials of low dose versus full dose LMWH are currently underway (NCT04372589, NCT04401293, NCT04367831, NCT04345848, NCT04373707, NCT04366960, NCT04359277 and NCT04397510) and will inform the future clinical management of COVID-19. However, in the context of diseases with a profound inflammatory response and potential lower levels of AT such as COVID-19 [8, 70], LMWH may not be effective. Indeed, anecdotal observations from clinicians caring for patients with COVID-19 report that patients continue to develop clinically identifiable clots, despite receiving prophylactic doses of LMWH, and that higher doses of heparin are needed according to factor Xa analysis, especially in patients with significantly elevated levels of D-dimer [98]. This suggests that it may be important to target coagulation proteinases that do not rely on the presence of circulating endogenous anticoagulants. In this context, some reports suggest that bivalirudin may improve haemofilter and extracorporeal membrane oxygenation filter survival $[99,100]$.

Direct oral anticoagulants that specifically inhibit thrombin and factor Xa are now available. These agents would not be suitable for all patients, particularly if drug interactions with potential antiviral medication are expected, or in mechanically ventilated patients requiring enteral feeding. Although rivaroxaban and apixaban can be delivered via a nasogastric tube to the stomach, they should not be mixed with enteral nutrition [101]. As with LMWH there is an increased risk of bleeding with direct oral anticoagulants but in COVID-19, complications related to bleeding are anecdotally not commonly seen, but a recent study has suggested an increased risk of bleeding in non-critically ill patients receiving heparin [102]. Hence the risk of bleeding complications may be lower for patients at increased risk of death with COVID-19 compared to other causes of severe sepsis/ARDS. Furthermore, idarucizumab and andexanet alfa are now available for the reversal of dabigatran and rivaroxaban/apixaban, respectively, mitigating the fear that the effects of these agents cannot be reversed should bleeding occur.

APC showed beneficial effects in the PROWESS study, particularly in the subgroup of patients with CAP and a high risk of death. Heterogeneity within patient populations has hampered previous studies of APC; any future trials in COVID-19 will need patients to be carefully sub-phenotyped because the benefit in COVID-19 will likely be seen in those at high risk of death with low endogenous levels of APC. Nebulised streptokinase has shown reduced mortality in one study of ARDS patients [79] and fibrinolysis is currently being targeted in COVID-19 with trials of nebulised and systemically administered tPA; these trials are welcomed and have the potential to reduce pulmonary microthrombi and lung injury.

Targeting $\mathrm{PAR}_{1}$ is another potential attractive approach that could counter the negative effects of both thrombin formation and activation of pro-inflammatory pathways by the coagulation system. Although $\mathrm{PAR}_{1}$ antagonists are unlikely to impact on VTE they could have beneficial effects in COVID-19 pneumonia through several potential mechanisms: 1) direct anti-platelet effect potentially reducing the incidence of coronary and cerebral artery thrombosis [103]; 2) inhibition of inflammatory signalling pathways downstream of thrombin resulting in attenuated inflammatory responses and inflammatory cell recruitment; 3) protection from the development of post-ARDS pulmonary fibrosis [104]; 4) maintaining integrity of the endothelial alveolar barrier, reducing pulmonary oedema; and 5) indirectly attenuating coagulation activation by reducing inflammation. Several $\mathrm{PAR}_{1}$ antagonists are in development but only one has been clinically approved, vorapaxar (Zontivity). Vorapaxar is a highly selective small molecule $\mathrm{PAR}_{1}$ antagonist but its long half-life $(20 \mathrm{~h})$ and inhibitory effects on platelets $(24-48 \mathrm{~h})[105,106]$ call for cautious use in critically ill patients, particularly because a reversal agent does not exist. Trials in the secondary prevention of acute coronary syndromes have shown that there is also potential for bleeding, although in these trials patients were on dual anti-platelet medication. $\mathrm{PAR}_{1}$ antagonism could therefore represent a potential approach to halt progression of the disease in hospitalised patients at risk of critical illness. Future research and carefully designed trials in this area would be welcomed. Table 1 provides a summary of the effects of therapeutics targeting coagulation proteinases in pneumonia, lung injury and sepsis in preclinical and clinical studies.

\section{Conclusions}

Preclinical studies have shown beneficial effects of targeting coagulation proteinases in models of pneumonia and lung injury and have added significant knowledge to the understanding of the crosstalk 
TABLE 1 Effects of endogenous anticoagulants or drugs targeting coagulation proteases: evidence from preclinical and clinical studies

Pathway

Agent

Animal study outcomes

Clinical study outcomes

Recruiting COVID-19

trials

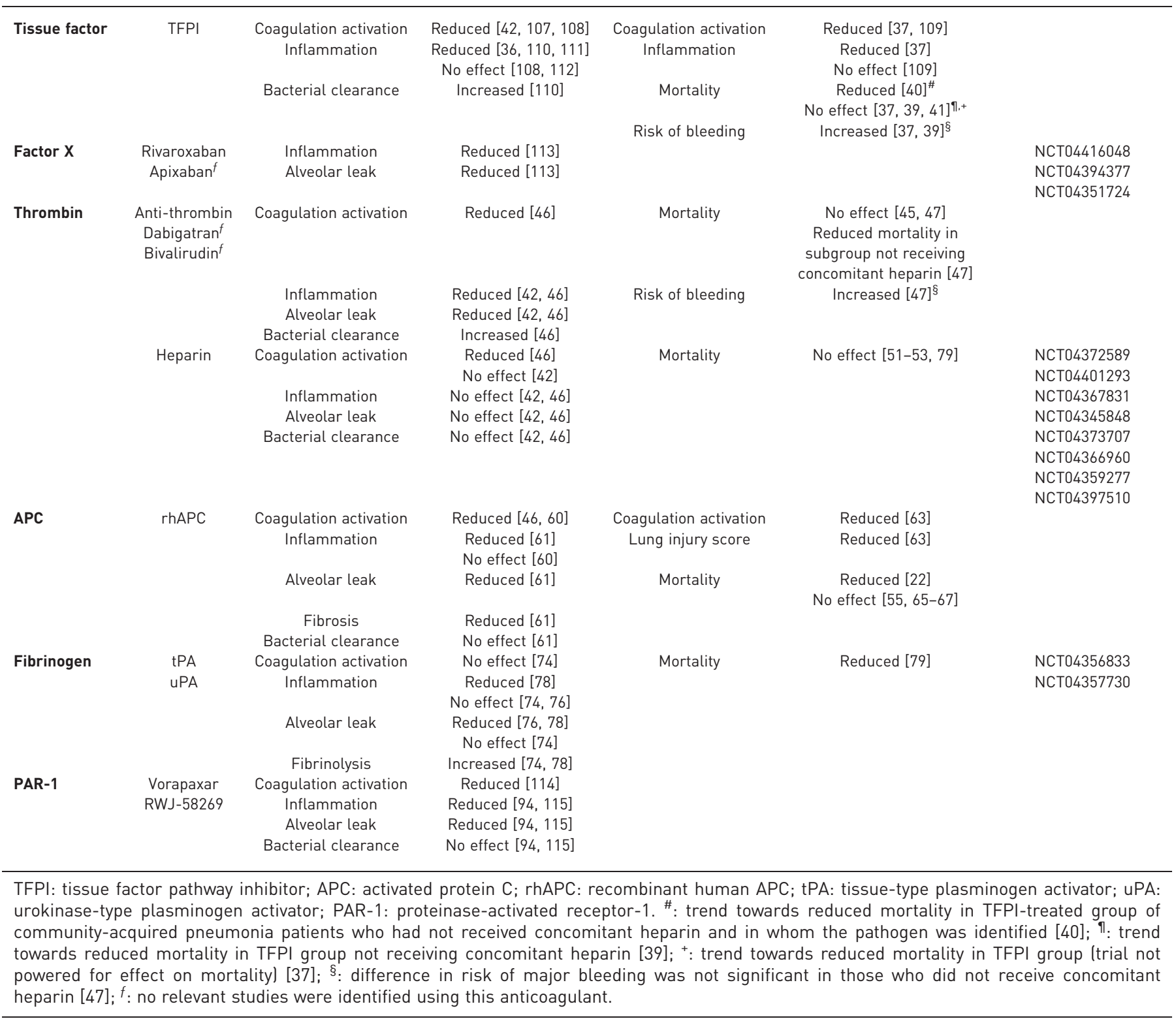

between coagulation and inflammation in the context of pulmonary infection, sepsis and lung injury. Importantly, these preclinical studies have limitations that affect the potential translation of findings to human disease, and previous clinical trials of endogenous anticoagulants in pneumonia and in sepsis have mostly failed to show benefits on mortality. However, in the context of COVID-19, the evidence of a profound hypercoagulable state with pathogenic contributions of both macrothrombi and microthrombi in severe disease suggest there is an improved risk/benefit ratio in targeting specific aspects of the coagulation pathways. The extensive body of research on coagulation and sepsis provides important background for the design of future trials in patients with COVID-19 pneumonia to assess whether targeting coagulation can reduce inflammation as well as VTE and microthrombi, and potentially affect survival. A large armamentarium of potentially beneficial agents exists, and well-designed randomised clinical trials are now needed to investigate the wide range of anticoagulant and anti-fibrinolytic therapies to determine the optimal strategy. 
Conflict of interest: R.J. José has nothing to disclose. A. Williams has nothing to disclose. A. Manuel has nothing to disclose. J.S. Brown has nothing to disclose. R.C. Chambers reports grants from The Medical Research Council UK, The Wellcome Trust and The Rosetrees Trust, during the conduct of the study.

\section{References}

1 Worldometer. COVID-19 Coronavirus Pandemic. www.worldometers.info/coronavirus/ Date last accessed: 1 June 2020.

RECOVERY Collaborative Group, Horby P, Lim WS, et al. Dexamethasone in hospitalized patients with COVID-19 - preliminary report. N Engl J Med 2020; in press [https://doi.org/10.1056/NEJMoa2021436]. Comashek KM, Dodd LE, et al. Remdesivir for the treat N Engl J Med 2020; in press [https://doi.org/10.1056/NEJMoa2007764] ( Calbo $\mathrm{E}$, Alsina M Rodríguez-Carballeira M, et al. The impact of time on the systemic inflammatory response in pneumococcal pneumonia. Eur Respir J 2010; 35: 614-618.

6 Chen N, Zhou M, Dong X, et al. Epidemiological and clinical characteristics of 99 cases of 2019 novel coronavirus pneumonia in Wuhan, China: a descriptive study. Lancet 2020; 395: 507-513.

7 Zhou F, Yu T, Du R, et al. Clinical course and risk factors for mortality of adult inpatients with COVID-19 in Wuhan, China: a retrospective cohort study. Lancet 2020; 395: 1054-1062.

8 Tang N, Li D, Wang X, et al. Abnormal coagulation parameters are associated with poor prognosis in patients with novel coronavirus pneumonia. J Thromb Haemost 2020; 18: 844-847.

9 Salluh JIF, Rabello LSCF, Rosolem MM, et al. The impact of coagulation parameters on the outcomes of patients with severe community-acquired pneumonia requiring intensive care unit admission. I Crit Care 2011; 26: 496-501.

10 Chen J, Wang X, Zhang S, et al. Findings of acute pulmonary embolism in COVID-19 patients. Lancet Infect Dis 2020; in press.

11 Lodigiani C, Iapichino G, Carenzo L, et al. Venous and arterial thromboembolic complications in COVID-19 patients admitted to an academic hospital in Milan, Italy. Thromb Res 2020; 191: 9-14.

12 Ackermann M, Verleden SE, Kuehnel M, et al. Pulmonary vascular endothelialitis, thrombosis, and angiogenesis in COVID-19. N Engl J Med 2020; 383: 120-128.

13 Leppkes M, Knopf J, Naschberger E, et al. Vascular occlusion by neutrophil extracellular traps in COVID-19. EBioMedicine 2020; 58: 102925.

14 Miesbach W. Pathological role of angiotensin II in severe COVID-19. TH Open 2020; 4: el38-e144.

15 Kernohan A, Calderon M. What Are The Risk Factors and Effectiveness of Prophylaxis for Venous Thromboembolism in COVID-19 Patients? - CEBM. www.cebm.net/covid-19/20200/ Date last accessed: 16 July 2020.

16 Liu J, Li S, Liu J, et al. Longitudinal characteristics of lymphocyte responses and cytokine profiles in the peripheral blood of SARS-CoV-2 infected patients. EBioMedicine 2020; 55: 102763.

17 Tijburg PNM, Ryan J, Stern DM, et al. Activation of the coagulation mechanism on tumor necrosis factor-stimulated cultured endothelial cells and their extracellular matrix: the role of flow and factor IX/IXa. J Biol Chem 1991; 266: 12067-12074

18 Kerr R, Stirling D, Ludlam CA. Interleukin 6 and haemostasis. Br J Haematol 2001; 115: 3-12.

19 Kellum JA, Kong L, Fink MP, et al. Understanding the inflammatory cytokine response in pneumonia and sepsis: results of the Genetic and Inflammatory Markers of Sepsis (GenIMS) study. Arch Intern Med 2012; 167: $1655-1663$.

20 Ewig S, de Roux A, Bauer T, et al. Validation of predictive rules and indices of severity for community acquired pneumonia. Thorax 2004; 59: 421-427.

21 Kojicic M, Li G, Hanson AC, et al. Risk factors for the development of acute lung injury in patients with infectious pneumonia. Crit Care 2012; 16: R46.

22 Laterre P-F, Garber G, Levy H, et al. Severe community-acquired pneumonia as a cause of severe sepsis: data from the PROWESS study. Crit Care Med 2005; 33: 952-961.

23 van Till JWO, Levi M, Bresser P, et al. Early procoagulant shift in the bronchoalveolar compartment of patients with secondary peritonitis. J Infect Dis 2006; 194: 1331-1339.

24 van der Poll T. Tissue factor as an initiator of coagulation and inflammation in the lung. Crit Care 2008; 12: Suppl. 6, S3.

25 Schultz MJ, Millo J, Levi M, et al. Local activation of coagulation and inhibition of fibrinolysis in the lung during ventilator associated pneumonia. Thorax 2004; 59: 130-135.

26 Bastarache JA, Wang L, Geiser T, et al. The alveolar epithelium can initiate the extrinsic coagulation cascade through expression of tissue factor. Thorax 2007; 62: 608-616.

27 Bastarache JA, Fremont RD, Kropski JA, et al. Procoagulant alveolar microparticles in the lungs of patients with acute respiratory distress syndrome. Am J Physiol Lung Cell Mol Physiol 2009; 297: L1035-L1041.

28 Giesen PL, Rauch U, Bohrmann B, et al. Blood-borne tissue factor: another view of thrombosis. Proc Natl Acad Sci USA 1999; 96: 2311-2315.

29 McVey MJ, Tabuchi A, Kuebler WM. Microparticles and acute lung injury. Am J Physiol Lung Cell Mol Physiol 2012; 303: L364-L381.

30 Günther A, Mosavi P, Heinemann S, et al. Alveolar fibrin formation caused by enhanced procoagulant and depressed fibrinolytic capacities in severe pneumonia. Comparison with the acute respiratory distress syndrome. Am J Respir Crit Care Med 2000; 161: 454-462.

31 Hoogerwerf JJ, de Vos AF, Bresser P, et al. Lung inflammation induced by lipoteichoic acid or lipopolysaccharide in humans. Am J Respir Crit Care Med 2008; 178: 34-41.

32 Monroe DM, Key NS. The tissue factor-factor VIIa complex: procoagulant activity, regulation, and multitasking. J Thromb Haemost 2007; 5: 1097-1105.

33 Crawley JTB, Lane DA. The haemostatic role of tissue factor pathway inhibitor. Arterioscler Thromb Vasc Biol 2008; 28: 233-242. 
Chambers RC, Scotton CJ. Coagulation cascade proteinases in lung injury and fibrosis. Proc Am Thorac Soc 2012; 9: 96-101.

Welty-Wolf KE, Carraway MS, Miller DL, et al. Coagulation blockade prevents sepsis-induced respiratory and renal failure in baboons. Am J Respir Crit Care Med 2001; 164: 1988-1996.

Miller DL, Welty-Wolf K, Carraway MS, et al. Extrinsic coagulation blockade attenuates lung injury and proinflammatory cytokine release after intratracheal lipopolysaccharide. Am J Respir Cell Mol Biol 2002; 26: 650-658.

Abraham E, Reinhart K, Svoboda P, et al. Assessment of the safety of recombinant tissue factor pathway inhibitor in patients with severe sepsis: a multicenter, randomized, placebo-controlled, single-blind, dose escalation study. Crit Care Med 2001; 29: 2081-2089.

Luo P, Liu Y, Qiu L, et al. Tocilizumab treatment in COVID-19: a single center experience. J Med Virol 2020; 92 $814-818$.

Abraham E, Reinhart K, Opal SM, et al. Efficacy and safety of tifacogin (recombinant tissue factor pathway inhibitor) in severe sepsis: a randomized controlled trial. JAMA 2003; 290: 238-247.

Laterre P-F, Opal SM, Abraham E, et al. A clinical evaluation committee assessment of recombinant human tissue factor pathway inhibitor (tifacogin) in patients with severe community-acquired pneumonia. Crit Care 2009; 13: R36.

Wunderink RG, Laterre P-F, Francois B, et al. Recombinant tissue factor pathway inhibitor in severe community-acquired pneumonia: a randomized trial. Am J Respir Crit Care Med 2011; 183: 1561-1568.

Choi G, Hofstra J-JH, Roelofs JJTH, et al. Antithrombin inhibits bronchoalveolar activation of coagulation and limits lung injury during Streptococcus pneumoniae pneumonia in rats. Crit Care Med 2008; 36: 204-210.

Hoffmann H, Siebeck M, Spannagl M, et al. Effect of recombinant hirudin, a specific inhibitor of thrombin, on endotoxin-induced intravascular coagulation and acute lung injury in pigs. Am Rev Respir Dis 1990; 142: 782-788.

Schmidt B, Davis $\mathrm{P}$, La Pointe $\mathrm{H}$, et al. Thrombin inhibitors reduce intrapulmonary accumulation of fibrinogen and procoagulant activity of bronchoalveolar lavage fluid during acute lung injury induced by pulmonary overdistention in newborn piglets. Pediatr Res 1996; 39: 798-804.

Afshari A, Wetterslev J, Brok J, et al. Antithrombin III for critically ill patients. Cochrane Database Syst Rev 2008; 2: CD005370

Hofstra JJ, Cornet AD, de Rooy BF, et al. Nebulized antithrombin limits bacterial outgrowth and lung injury in Streptococcus pneumoniae pneumonia in rats. Crit Care 2009; 13: R145-R145.

Warren BL, Eid A, Singer P, et al. High-dose antithrombin III in severe sepsis. JAMA 2001; 286: 1869-1878.

Obi AT, Tignanelli CJ, Jacobs BN, et al. Empirical systemic anticoagulation is associated with decreased venous thromboembolism in critically ill influenza A H1N1 acute respiratory distress syndrome patients. J Vasc Surg Venous Lymphat Disord 2019; 7: 317-324.

Poterucha TJ, Libby P, Goldhaber SZ. More than an anticoagulant: do heparins have direct anti-inflammatory effects? Thromb Haemost 2017; 117: 437-444.

Lang J, Yang N, Deng J, et al. Inhibition of SARS pseudovirus cell entry by lactoferrin binding to heparan sulfate proteoglycans. PLoS One 2011; 6: e23710.

Dixon B, Santamaria JD, Campbell DJ. A phase 1 trial of nebulised heparin in acute lung injury. Crit Care 2008 12: R64.

Dixon B, Schultz MJ, Smith R, et al. Nebulized heparin is associated with fewer days of mechanical ventilation in critically ill patients: a randomized controlled trial. Crit Care 2010; 14: R180.

Dixon B, Smith R, Santamaria JD, et al. A trial of nebulised heparin to limit lung injury following cardiac surgery. Anaesth Intensive Care 2016; 44: 28-33.

Dhainaut J-F, Yan SB, Joyce DE, et al. Treatment effects of drotrecogin alfa (activated) in patients with severe sepsis with or without overt disseminated intravascular coagulation. J Thromb Haemost 2004; 2: 1924-1933. Med 2012: 2055-2064. Vincent J, Bernard GR, Beale R, et al. Drotrecogin alfa (activated) treatment in severe sepsis from the global open-label trial ENHANCE: further evidence for survival and safety and implications for early treatment. Crit Care Med 2005; 33: 2266-2277.

Esmon CT, Ding W, Yasuhiro K, et al. The protein C pathway: new insights. Thromb Haemost 1997; 78: 70-74. Rijneveld AW, Weijer S, Florquin S, et al. Thrombomodulin mutant mice with a strongly reduced capacity to generate activated protein $\mathrm{C}$ have an unaltered pulmonary immune response to respiratory pathogens and lipopolysaccharide. Blood 2004; 103: 1702-1709.

Taylor FB, Chang A, Esmon CT, et al. Protein C prevents the coagulopathic and lethal effects of Escherichia coli infusion in the baboon. J Clin Invest 1987; 79: 918-925. injury by inhibiting activated leukocytes in rats. Blood 1996; 87: 642-647.

H, Gabazza EC, Tamaki S, et al. Intratracheal administration of activated protein C inhibit bleomycin-induced lung fibrosis in the mouse. Am J Respir Crit Care Med 2001; 163: 1660-1668.

Mandell LA, Wunderink RG, Anzueto A, et al. Infectious Diseases Society of America/American Thoracic Society consensus guidelines on the management of community-acquired pneumonia in adults. Clin Infect Dis 2007; 44: Suppl. 2, S27-S72.

Cornet AD, Hofstra JJ, Vlaar AP, et al. Activated protein C attenuates pulmonary coagulopathy in patients with acute respiratory distress syndrome. J Thromb Haemost 2013; 11: 894-901.

Cornet AD, Groeneveld ABJ, Hofstra JJ, et al. Recombinant human activated protein $\mathrm{C}$ in the treatment of acute respiratory distress syndrome: a randomized clinical trial. PLoS One 2014; 9: e90983. injury. Am J Respir Crit Care Med 2008; 178: 618-623.

Abraham E, Laterre p-F, Garg R, et al. Drotrecogin alfa (activated) for adults with severe sepsis and a low risk of death. N Engl J Med 2005; 353: 1332-1341. 

Database Syst Rev 2011; 3: CD004388.

68 Kalil AC, Florescu DF. Severe sepsis: are PROWESS and PROWESS-SHOCK trials comparable? A clinical and statistical heterogeneity analysis. Crit Care 2013; 17: 167.

69 Kerschen EJ, Fernandez JA, Cooley BC, et al. Endotoxemia and sepsis mortality reduction by non-anticoagulant activated protein C. J Exp Med 2007; 204: 2439-2448.

70 Panigada M, Bottino N, Tagliabue P, et al. Hypercoagulability of COVID-19 patients in intensive care unit A report of thromboelastography findings and other parameters of hemostasis. J Thromb Haemost 2020; 18: $1738-1742$.

71 Choi G, Schultz MJ, van Till JWO, et al. Disturbed alveolar fibrin turnover during pneumonia is restricted to the site of infection. Eur Respir J 2004; 24: 786-789.

72 Rijneveld AW, Florquin S, Bresser P, et al. Plasminogen activator inhibitor type-1 deficiency does not influence the outcome of murine pneumococcal pneumonia. Blood 2003; 102: 934-939.

73 Renckens R, Roelofs JJTH, Bonta PI, et al. Plasminogen activator inhibitor type 1 is protective during severe Gram-negative pneumonia. Blood 2007; 109: 1593-1601.

74 Hofstra JJ, Cornet AD, Declerck PJ, et al. Nebulized fibrinolytic agents improve pulmonary fibrinolysis but not inflammation in rat models of direct and indirect acute lung injury. PLoS One 2013; 8: e55262.

75 Rijneveld AW, Levi M, Florquin S, et al. Urokinase receptor is necessary for adequate host defense against pneumococcal pneumonia. J Immunol 2002; 168: 3507-3511.

76 Stringer KA, Hybertson BM, Cho OJ, et al. Tissue plasminogen activator (tPA) inhibits interleukin-1 induced acute lung leak. Free Radic Biol Med 1998; 25: 184-188.

77 Berri F, Rimmelzwaan GF, Hanss M, et al. Plasminogen controls inflammation and pathogenesis of influenza virus infections via fibrinolysis. PLoS Pathog 2013; 9: e1003229.

78 Liu C, Ma Y, Su Z, et al. Meta-analysis of preclinical studies of fibrinolytic therapy for acute lung injury. Front Immunol 2018; 9: 1898.

79 Mahmoud AAA, Mahmoud HE, Mahran MA, et al. Streptokinase versus unfractionated heparin nebulization in patients with severe acute respiratory distress syndrome (ARDS): a randomized controlled trial with observational controls. J Cardiothorac Vasc Anesth 2020; 34: 436-443.

80 José RJ, Williams AE, Chambers RC. Proteinase-activated receptors in fibroproliferative lung disease. Thorax 2014; 69: 190-192.

81 Riewald M, Petrovan RJ, Donner A, et al. Activation of endothelial cell protease activated receptor 1 by the protein C pathway. Science 2002; 296: 1880-1882.

82 Kuliopulos A, Covic L, Seeley SK, et al. Plasmin desensitization of the $\mathrm{PAR}_{1}$ thrombin receptor: kinetics, sites of truncation, and implications for thrombolytic therapy. Biochemistry 1999; 38: 4572-4585.

83 Boire A, Covic L, Agarwal A, et al. $\mathrm{PAR}_{1}$ is a matrix metalloprotease-1 receptor that promotes invasion and tumorigenesis of breast cancer cells. Cell 2005; 120: 303-313.

84 Naldini A, Carney DH, Pucci A, et al. Thrombin regulates the expression of proangiogenic cytokines via proteolytic activation of protease-activated receptor-1. Gen Pharmacol 2000; 35: 255-259.

85 Chi L, Li Y, Stehno-Bittel L, et al. Interleukin-6 production by endothelial cells via stimulation of protease-activated receptors is amplified by endotoxin and tumor necrosis factor-alpha. J Interferon Cytokine Res 2001; 21: 231-240.

86 Niessen F, Furlan-Freguia C, Fernández JA, et al. Endogenous EPCR/aPC-PAR ${ }_{1}$ signaling prevents inflammation-induced vascular leakage and lethality. Blood 2009; 113: 2859-2866.

87 Singleton PA, Moreno-Vinasco L, Sammani S, et al. Attenuation of vascular permeability by methylnaltrexone: role of mOP-R and S1P3 transactivation. Am J Respir Cell Mol Biol 2007; 37: 222-231.

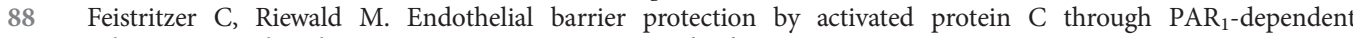
sphingosine 1-phosphate receptor-1 crossactivation. Blood 2005; 105: 3178-3184.

89 Ludeman MJ, Kataoka $\mathrm{H}$, Srinivasan $\mathrm{Y}$, et al. $\mathrm{PAR}_{1}$ cleavage and signaling in response to activated protein $\mathrm{C}$ and thrombin. J Biol Chem 2005; 280: 13122-13128.

90 Schuepbach RA, Feistritzer C, Fernández JA, et al. Protection of vascular barrier integrity by activated protein C in murine models depends on protease-activated receptor-1. Thromb Haemost 2009; 101: 724-733.

91 Schuepbach RA, Madon J, Ender M, et al. Protease-activated receptor-1 cleaved at R46 mediates cytoprotective effects. J Thromb Haemost 2012; 10: 1675-1684.

92 Mosnier LO, Sinha RK, Burnier L, et al. Biased agonism of protease-activated receptor 1 by activated protein C caused by noncanonical cleavage at Arg46. Blood 2012; 120: 5237-5246.

93 Kaneider NC, Leger AJ, Agarwal A, et al. 'Role reversal' for the receptor $\mathrm{PAR}_{1}$ in sepsis-induced vascular damage. Nat Immunol 2007; 8: 1303-1312.

94 José RJ, Williams AE, Mercer PF, et al. Regulation of neutrophilic inflammation by proteinase-activated receptor 1 during bacterial pulmonary infection. J Immunol 2015; 194: 6024-6034.

95 Antoniak S, Owens AP, Baunacke M, et al. PAR-1 contributes to the innate immune response during viral infection. J Clin Invest 2013; 123: 1310-1322.

96 Khoufache K, Berri F, Nacken W, et al. $\mathrm{PAR}_{1}$ contributes to influenza A virus pathogenicity in mice. J Clin Invest 2013; 123: 206-214.

97 Lachant DJ, Lachant NA, Kouides P, et al. Chronic therapeutic anticoagulation is associated with decreased thrombotic complications in SARS-CoV-2 infection. J Thromb Haemost 2020; in press [https://doi.org/10.1111/ jth.15032].

98 Levi M, Thachil J, Iba T, et al. Coagulation abnormalities and thrombosis in patients with COVID-19. Lancet Haematol 2020; 7: e438-e440.

99 Seelhammer TG, Rowse P, Yalamuri S. Bivalirudin for maintenance anticoagulation during venovenous extracorporeal membrane oxygenation for COVID-19. J Cardiothorac Vasc Anesth 2020; in press [https:doi/org/ 10.1053/j.jvca.2020.06.059].

100 Kiser TH, MacLaren R, Fish DN, et al. Bivalirudin versus unfractionated heparin for prevention of hemofilter occlusion during continuous renal replacement therapy. Pharmacotherapy 2010; 30: 1117-1126.

101 Peterson JJ, Hoehns JD. Administration of direct oral anticoagulants through enteral feeding tubes. $J$ Pharm Technol 2016; 32: 196-200. 
102 Pesavento R, Ceccato D, Pasquetto G, et al. The hazard of (sub)therapeutic doses of anticoagulants in non-critically ill patients with COVID-19: the Padua province experience. J Thromb Haemost 2020; in press [https:doi.org/10.1111/jth.15022].

103 Morrow DA, Braunwald E, Bonaca MP, et al. Vorapaxar in the secondary prevention of atherothrombotic events. N Engl J Med 2012; 366: 1404-1413.

104 Howell DCJ, Johns RH, Lasky JA, et al. Absence of proteinase-activated receptor-1 signaling affords protection from bleomycin-induced lung inflammation and fibrosis. Am J Pathol 2005; 166: 1353-1365.

105 Becker RC, Moliterno DJ, Jennings LK, et al. Safety and tolerability of SCH 530348 in patients undergoing non-urgent percutaneous coronary intervention: a randomised, double-blind, placebo-controlled phase II study. Lancet 2009; 373: 919-928.

106 Ramachandran R. Developing $\mathrm{PAR}_{1}$ antagonists: minding the endothelial gap. Discov Med 2012; 13: 425-431.

107 van den Boogaard FE, Hofstra JJ, van 't Veer C, et al. Feasibility and safety of local treatment with recombinant human tissue factor pathway inhibitor in a rat model of Streptococcus pneumoniae pneumonia. PLoS One 2015; 10: $\mathrm{e} 0127261$.

108 Levi M, ten Cate H, Bauer KA, et al. Inhibition of endotoxin-induced activation of coagulation and fibrinolysis by pentoxifylline or by a monoclonal anti-tissue factor antibody in chimpanzees. J Clin Invest 1994; 93: 114-120.

109 de Jonge E, Dekkers PE, Creasey AA, et al. Tissue factor pathway inhibitor does not influence inflammatory pathways during human endotoxemia. J Infect Dis 2001; 183: 1815-1818.

110 van den Boogaard FE, Hofstra JJ, Brands X, et al. Nebulized recombinant human tissue factor pathway inhibitor attenuates coagulation and exerts modest anti-inflammatory effects in rat models of lung injury. J Aerosol Med Pulm Drug Deliv 2017; 30: 91-99.

111 Creasey AA, Chang AC, Feigen L, et al. Tissue factor pathway inhibitor reduces mortality from Escherichia coli septic shock. J Clin Invest 1993; 91: 2850-2860.

112 Weijer S, Schoenmakers SHHF, Florquin S, et al. Inhibition of the tissue factor/factor VIIa pathway does not influence the inflammatory or antibacterial response to abdominal sepsis induced by Escherichia coli in mice. J Infect Dis 2004; 189: 2308-2317.

113 Shi M, Wang L, Zhou J, et al. Direct factor Xa inhibition attenuates acute lung injury progression via modulation of the PAR-2/NF- $\mathrm{KB}$ signaling pathway. Am J Transl Res 2018; 10: 2335-2349.

114 José R, Williams A, Sulikowski M, et al. Regulation of neutrophilic inflammation in lung injury induced by community-acquired pneumonia. Lancet 2015; 385: Suppl. 1, S52.

115 Mercer PF, Williams AE, Scotton CJ, et al. Proteinase-activated receptor-1, CCL2, and CCL7 regulate acute neutrophilic lung inflammation. Am J Respir Cell Mol Biol 2014; 50: 144-157. 